\title{
Review of Biochemical and Nutritional Constituents in Different Green Leafy Vegetables in Oman
}

\author{
Vijaya Saradhi Settaluri*, Kholood Mohammed Khalaf Al-Mamari, \\ Salwa Ibrahim Mohammed Al-Balushi, Moza Khamis Zayid Al-Risi, \\ Muhammad Behjat Ali \\ Biology Section, Department of Applied Sciences, Higher College of Technology, Muscat, Sultanate of Oman \\ Email: Vijaya.settaluri@hct.edu.om
}

Received 18 May 2015; accepted 9 June 2015; published 12 June 2015

Copyright (C) 2015 by authors and Scientific Research Publishing Inc. This work is licensed under the Creative Commons Attribution International License (CC BY). http://creativecommons.org/licenses/by/4.0/

(c) (i) Open Access

\section{Abstract}

Green leafy vegetables are very nutrient-dense and incredibly healthy. They are vital sources of antioxidants and they are the best which are very beneficial to providing weight loss and maintenance, because it keeps you feeling full and helps control your hunger. Also, leafy vegetables are full of fiber, vitamins; minerals and substances that help protect you from disease [1] [2]. For this we choose five types of vegetables which are lettuce, cabbage, parsley, spinach and arugula to estimate some nutritional values present on them such as: carbohydrate (sucrose, fructose, glucose and starch), protein, amino acids (lysine and phenyl alanine), vitamin C (ascorbic acid) and lipid. The results obtained were analyzed and the relative percentages of these compounds were tabulated. Among the five green leafy vegetables the glucose content was highest in lettuce and was least in arugula. Among the five green leafy vegetables the fructose content was highest in parsley and was least in cabbage. Among the five green leafy vegetables the sucrose content was highest in parsley and was least in cabbage. Among the five green leafy vegetables the starch content was highest in lettuce and was least in spinach. Among the five green leafy vegetables the ascorbic acid content was highest in lettuce and was least in parsley and arugula. Among the five green leafy vegetables the protein content was highest in parsley and was least in cabbage. Among the five green leafy vegetables the lysine content was highest in cabbage and was least in arugula. Among the five green leafy vegetables the phenyl alanine content was highest in cabbage and was least in spinach. Among the five green leafy vegetables the lipid content was highest in lettuce and was least in cabbage.

${ }^{*}$ Corresponding author.

How to cite this paper: Settaluri, V.S., Al-Mamari, K.M.K., Al-Balushi, S.I.M., Al-Risi, M.K.Z. and Ali, M.B. (2015) Review of Biochemical and Nutritional Constituents in Different Green Leafy Vegetables in Oman. Food and Nutrition Sciences, 6, 765-769. http://dx.doi.org/10.4236/fns.2015.69079 
Keywords

Nutritional Value, Protein, Carbohydrate, Vitamins, Analysis, Comparison

\section{Introduction}

It has been known for a long time that green leafy vegetables are very rich sources of antioxidants. The extracts of green leafy vegetables have proved vital in curing diseases like asthma. These are highly essential for developing resistance by allowing the immune system to function in a systematic manner. Some plant chemicals are capable of treating inflammatory disorders and eliminate carcinogens, while many other leafy vegetables regulate the rate at which cells reproduce, get rid of old cells and maintain DNA. In a country like Oman there are a few farmers who cultivate such green leafy vegetables, and this evinces the interest in authors to focus on the present study. Another reason is that though most of the land is a desert and there is very little fertile land. Thus it is of significance to establish the nutritional parameters in these green leafy vegetables. This is because leafy vegetables are full of fiber (an important nutrient for weight loss which can also lower cholesterol and blood pressure, and help to temper blood-sugar swings by slowing the absorption of carbohydrates into your bloodstream after meals) along with vitamins, minerals, and plant-based substances that help protect you from heart disease, diabetes, and even cancer. This lowers your risk of cardiovascular disease and type 2 diabetes. Leafy greens also contain a lot of water, which helps keep you hydrated and contributes to beautiful skin and hair (one should consume a diet rich in B vitamins like salmon, sardines, legumes and whole grains, along with fortified cereals and breads, seeds and dark green leafy vegetables). Rich sources of omega-3 like flaxseed, canola oils, wheat germ and soya beans, along with nuts, citrus fruits, brightly coloured vegetables, mushrooms (rich in selenium), and magnesium-rich foods like spinach, dark green leafy vegetables should be preferred. Foods rich in sugar and hydrogenated fats loaded with empty calories should be avoided [3].

Cabbage is an excellent source of vitamin C and vitamin $\mathrm{K}$, containing more than $20 \%$ of the daily value for each of these nutrients per serving [4]. Cabbage is also a good source of dietary fiber, vitamin B6 and folate, with no other nutrients having significant content per 100 gram serving. Dark green lettuces include romaine, green leaf, arugula and butter head. These nutrient-dense leaves are crisp and slightly bitter, and most people use them to make raw salads [5].

Dark lettuces are rich in vitamins A, C and K; eating them regularly will improve your eyesight, bone health and skin elasticity while helping your blood to clot normally. On combining these dark leaves with tomatoes, onions, carrots and cucumbers, a colorful, healthy salad can be created [6]. Spinach is one of the most nutritious foods available, as it is low in calories and high in vitamins; spinach is one of the most nutrient-dense foods in existence. It's packed with vitamins A and C, as well as foliate. And because heat reduces the green's oxalate content, freeing up its dietary calcium [7], cooked spinach gives you more nutrition than raw, but is excellent eaten raw in salads. Bags of frozen chopped spinach are more convenient to use than block kinds, and this mild-flavored vegetable can be added to soups, pasta dishes, and casseroles. It contains more than a dozen individual flavonoid compounds, which work together as cancer-fighting antioxidants [8].

Arugula is a cruciferous and leafy green vegetable with a peppery taste and is often used in salads. It is a good source of potassium, a mineral involved in managing blood pressure and preventing osteoporosis. Arugula may help boost memory due to phytochemicals-antioxidants found in all cruciferous vegetables. Like other salad greens, arugula is very low in calories, making it a great addition to any weight-loss plan.

Parsley keeps your immune system strong, tones your bones and heals the nervous system, too. It helps flush out excess fluid from the body, thus supporting kidney function. Regular use of parsley can help control your blood pressure. Parsley essential oil, when massaged into the scalp, may reduce hair loss. Parsley is a source of flavonoid, antioxidants, apigenin, folic acid, vitamin $\mathrm{K}$, vitamin C, and vitamin A [9].

\section{Materials and Methods}

\subsection{Instrumentation}

After due calibration of the instrument, spectral and absorbance measurements were made using Thermo UV 
visible double beam spectrophotometer bearing model number UVA-144294 (Helios alpha) made in England.

\subsection{Green Leafy Vegetables Extraction}

$5 \mathrm{~g}$ of (lettuce, cabbage, parsley, spinach and arugula) was weighed and cut into small pieces. By using pestle and mortar the $5 \mathrm{~g}$ of each vegetable was crushed with few drops of $70 \%$ ethanol. The crushed material was filtered first with cheese cloth then by filter paper. The filtered extract was transferred to $100 \mathrm{ml}$ volumetric flask by using funnel. Finally the volume was made to $100 \mathrm{ml}$ by $70 \%$ ethanol.

\subsection{Materials and Methods for Estimation of Biomolecules}

For methods 1, 2 and 3 di nitro salicylic acid reagent was used.

Preparation of the Reagent: $\mathrm{NaOH}$ solution: $20 \mathrm{mg}$ of $\mathrm{NaOH}$ was added with $250 \mathrm{ml}$ of distilled water.

DNS solution: $1.5 \mathrm{~g}$ of DNS was dissolved in $30 \mathrm{ml}$ of $\mathrm{NaOH}$ with stir on hot plate and then was filtrated by filter paper in volumetric flask. DNS reagent: $75 \mathrm{ml}$ of DNS solution was mixed with $30 \mathrm{ml}$ of $1 \%$ sodium potassium tartarate solution

Method-1 Estimation of Glucose [10]: Glucose: $250 \mathrm{mg}$ glucose was put in $100 \mathrm{ml}$ volumetric flask and made to $100 \mathrm{ml}$ by distilled water. In tubes $2 \mathrm{ml}$ of (glucose, blank, lettuce extraction, cabbage extraction, parsley extraction, arugula extraction and spinach extraction) was put one in each tube. Then $2 \mathrm{ml}$ of DNS reagent was added for each one. Finally optical density of each solution was taken by using spectrophotometer.

Method-2 Estimation of Fructose [10]: Fructose: $250 \mathrm{mg}$ Fructose was put in $100 \mathrm{ml}$ volumetric flask and made to $100 \mathrm{ml}$ by distilled water. In tubes $2 \mathrm{ml}$ of (fructose, blank, lettuce extraction, cabbage extraction, parsley extraction, arugula extraction and spinach extraction) was put one in each tube. Then $2 \mathrm{ml}$ of DNS reagent was added for each one. Finally optical density of each solution was taken by using spectrophotometer.

Method-3 Estimation of Sucrose [10]: $100 \mathrm{mg}$ of sucrose was added to $100 \mathrm{ml}$ of distilled water in $250 \mathrm{ml}$ beaker. From this $10 \mathrm{ml}$ was diluted to $100 \mathrm{ml}$ distilled water. And from this $2 \mathrm{ml}$ was taken to tube with $0.5 \mathrm{ml}$ of concentration $\mathrm{HCl}$. Then DNS reagent was added to the neutralized solution until the orange color was appeared. Finally, the absorbance was read at $750 \mathrm{~nm}$.

Method-4 Estimation of Lysine: $0.2 \mathrm{~g}$ of ninhydrin was added to $100 \mathrm{ml}$ of acetone. $100 \mathrm{mg}$ of lysine was added to $100 \mathrm{ml}$ of distilled water. From this $10 \mathrm{ml}$ was taken with $100 \mathrm{ml}$ of distilled water. In tubes $2 \mathrm{ml}$ of (lysine, blank, lettuce extraction, cabbage extraction, parsley extraction, arugula extraction and spinach extraction) was put one in each tube. Then $3 \mathrm{ml}$ of ninhydrin reagent was added for each one. Finally optical density of each solution was read by using spectrophotometer.

Method-5 Estimation of Phenyl Alanine: $0.2 \mathrm{~g}$ of ninhydrin was added to $100 \mathrm{ml}$ of acetone. $100 \mathrm{mg}$ of phenyl alanine was added to $100 \mathrm{ml}$ of distilled water. From this $10 \mathrm{ml}$ was taken with $100 \mathrm{ml}$ of distilled water. In tubes $2 \mathrm{ml}$ of (phenyl alanine, blank, lettuce extraction, cabbage extraction, parsley extraction, arugula extraction and spinach extraction) was put one in each tube. Then $3 \mathrm{ml}$ of ninhydrin reagent was added for each one. Finally optical density of each solution was read by using spectrophotometer.

Method-6 Estimation of Protein [11]: $500 \mathrm{mg}$ of burin albumin was added to $100 \mathrm{ml}$ of distilled water. In tubes $2 \mathrm{ml}$ of (Burin albumin, blank, lettuce extraction, cabbage extraction, parsley extraction, arugula extraction and spinach extraction) was put one in each tube. Then $3 \mathrm{ml}$ of biuret reagent was added for each one. 20 minutes was waited before optical density of each solution was taken by using spectrophotometer at $540 \mathrm{~nm}$.

Method-7 Estimation of Lipid [12]-[14]: 3 g of dry (lettuce extraction, cabbage extraction, parsley extraction, arugula extraction and spinach extraction) was put in extraction apparatus for 6 to 7 hours and then the residue was weighed to calculate the crude lipid.

Method-8 Estimation of Starch [15]: $1 \mathrm{~g}$ of anthrone was dissolved in $150 \mathrm{ml}$ of $72 \%$ sulphuric acid and then was put in fridge to cool. In tubes $2 \mathrm{ml}$ of (starch, blank, lettuce extraction, cabbage extraction, parsley extraction, arugula extraction and spinach extraction) was added to $5 \mathrm{ml}$ of $1.1 \% \mathrm{HCl}$ in each tube. Then these tubes were heated in water bath for $30 \%$. After that these solutions was diluted with $10 \mathrm{ml}$ distilled water. $1 \mathrm{ml}$ of solution was pipetted and was cooled them. $5 \mathrm{ml}$ of ice-cold anthrone reagent was added to solutions in tubes. Then for 11 minutes was heated in water bath. They were cooled again rapidly and finally the absorbance was read at $630 \mathrm{~nm}$.

Method-9 Estimation of Ascorbic Acid [16] [17]: $200 \mathrm{mg}$ of ascorbic acid was dissolved in $100 \mathrm{ml}$ of water. $2 \mathrm{~g}$ of potassium iodide was added in $100 \mathrm{ml}$ beaker with $1.3 \mathrm{~g}$ of iodine and was dissolved by put few milliliters 
of water and swirl for few minutes until iodine is dissolved. The iodine then was transferred to $100 \mathrm{ml}$ volumetric flask and was made to $100 \mathrm{ml}$ by distilled water. $0.25 \mathrm{~g}$ of starch was dissolved in $50 \mathrm{ml}$ boiling water. Put it to cool after dissolved. In conical flasks $20 \mathrm{ml}$ of (blank, ascorbic acid, lettuce extraction, cabbage extraction, parsley extraction, arugula extraction and spinach extraction) was put one in each conical flask. Then $150 \mathrm{ml}$ of distilled water was added for each except blank and ascorbic acid. $2 \mathrm{ml}$ of starch indicator was added for each. Then they were titrated until blue dark color was appeared.

\section{Results and Discussion}

The Figure 1 explains that nutritional value of all the green leafy vegetables in a nut shell. In lettuce the lipid, starch and sucrose content is significantly high and the other constituents are very low. Cabbage shows that starch and lipid are mostly high. As observed from the graph, for parsley lipid percentage is more when compared to others. The spinach shows that sucrose and lipid are in high level in spinach and the others all low. While for arugula the lipid, starch and sucrose are having more nutritional values present in it and glucose, ascorbic acid and lysine are present in low level. Among the five green leafy vegetables the glucose content was highest in lettuce and was least in arugula. Among the five green leafy vegetables the fructose content was highest in parsley and was least in cabbage. Among the five green leafy vegetables the sucrose content was highest in parsley and was least in cabbage. Among the five green leafy vegetables the starch content was highest in lettuce and was least in spinach. Among the five green leafy vegetables the ascorbic acid content was highest in lettuce and was least in parsley and arugula. Among the five green leafy vegetables the protein content was highest in parsley [18] and was least in cabbage. Among the five green leafy vegetables the lysine content was highest in cabbage [19] and was least in arugula. Among the five green leafy vegetables the phenyl alanine content was highest in cabbage and was least in spinach. Among the five green leafy vegetables the lipid content was highest in lettuce and was least in cabbage. Table 1 explains the summary of nutritional values in the five leafy green vegetables.

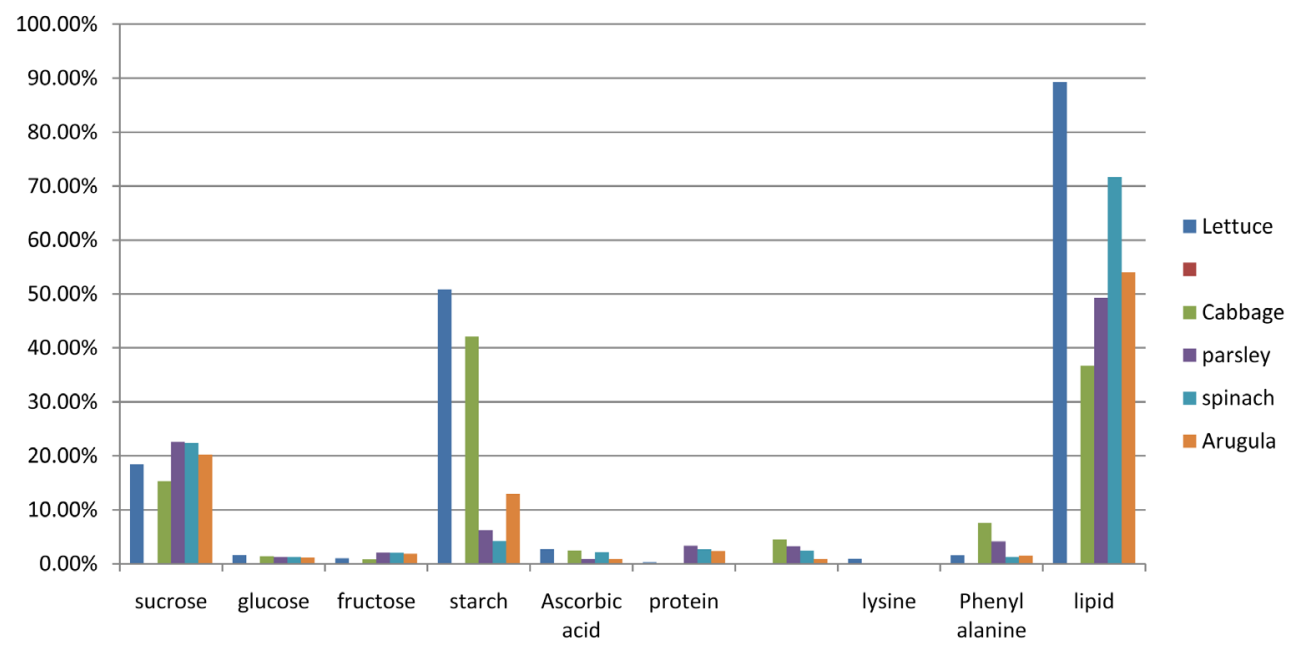

Figure 1. Summary of nutritional values in the five leafy green vegetables.

Table 1. Summary of nutritional values in the five leafy green vegetables.

\begin{tabular}{cccccccccc}
\hline Veg. & Sucrose & Glucose & Fructose & Starch & Ascorbic acid & Protein & Lysine & Phenyl alanine & Lipid \\
\hline Lettuce & $18.41 \%$ & $1.66 \%$ & $0.99 \%$ & $50.83 \%$ & $2.687 \%$ & $0.251 \%$ & $0.945 \%$ & $1.595 \%$ & $89.3 \%$ \\
Cabbage & $15.24 \%$ & $1.375 \%$ & $0.827 \%$ & $42.083 \%$ & $2.5 \%$ & $0.065 \%$ & $4.486 \%$ & $7.568 \%$ & $36.67 \%$ \\
parsley & $22.59 \%$ & $1.226 \%$ & $2.038 \%$ & $6.25 \%$ & $0.875 \%$ & $3.331 \%$ & $3.261 \%$ & $4.105 \%$ & $49.33 \%$ \\
spinach & $22.38 \%$ & $1.215 \%$ & $2.0197 \%$ & $4.17 \%$ & $2.125 \%$ & $2.627 \%$ & $2.433 \%$ & $1.215 \%$ & $71.67 \%$ \\
Arugula & $20.198 \%$ & $1.097 \%$ & $1.823 \%$ & $12.92 \%$ & $0.875 \%$ & $2.391 \%$ & $0.922 \%$ & $1.55 \%$ & $54 \%$ \\
\hline
\end{tabular}




\section{Conclusion}

The lipid, starch and sucrose were the most nutrient values in green leafy vegetables that were chosen (lettuce, cabbage, parsley, spinach and arugula) and the fructose, glucose and ascorbic acid were the least. The lettuce is the leafy vegetable that has most nutrient values and the least one is arugula.

\section{Acknowledgements}

The authors are grateful to the ministry of manpower for supporting the proposed research activity and to the higher management, faculty and technicians of Biology division of Department of Applied Sciences, Higher college of Technology for their continuous support and encouragement and for providing the necessary infrastructure facilities for executing this work.

\section{References}

[1] Park, Y., Subar, A.F., Hollenbeck, A. and Schatzkin, A. (2013) Dietary Fiber Intake and Mortality in the NIH-AARP Diet and Health Study. Archives of Internal Medicine, 171, 1061-1068.

[2] Enker, W. (2013) Bowel Function—Dietary Fiber. Mount Sinai. http://www.wehealny.org/healthinfo/dietaryfiber/

[3] Seth, M. (2015) A Nutritionist and Weight Loss Consultant at the Al Raffah Hospital. Muscat Media Group, Times of Oman.

[4] US Department of Agriculture (2014) USDA Database Table for Raw Cabbage, 100 g. National Nutrient Database for Standard Reference, Version SR-27.

[5] US Department of Agriculture and US Department of Health and Human Services (2010) Dietary Guidelines for Americans.

[6] Brown, T. and Media, D. (2015) List of Dark Green Leafy Vegetables. http://www.livestrong.com/article/358248-list-of-dark-green-leafy-vegetables/

[7] Sa'eed, M.D. and Abdullahi, M.R. (2012) Calcium and Iron Levels in Some Fruits and Vegetables Commonly Consumed in Kano Metropolis, Nigeria. Bayero Journal of Pure and Applied Sciences, 5, 57-59.

[8] Nierenberg, C. (2014) Leafy Greens-Ranked and Rated. The Edible Edition.

[9] Meyer, H., Bolarinwa, A., Wolfram, G. and Linseisen, J. (2006) Bioavailability of Apigenin from Apiin-Rich Parsley in Humans. Annals of Nutrition and Metabolism, 50, 167-172. http://dx.doi.org/10.1159/000090736

[10] Mannem, K., Madhu, Ch., Asha, V.S. and Kumar, V.P. (2012) Quantitative Evaluation of Carbohydrate Levels in Green Leafy Vegetables for Home Use by Uv-Visible Spectrophotometer. International Journal of Scientific \& Engineering Research, 3, 1-2.

[11] Malviya, S.N., Malakar, R., Yadav, M., Mishra, A. and Tiwari, A. (2011) Estimation and Characterization of Protein Present in Seed Extract of Jatropha curcas. Advance Research in Pharmaceuticals and Biologicals, 1, 35-44.

[12] Academy of Nutrition and Dietetics (2013) It’s about Eating Right-Fiber. AND, Chicago.

[13] Ehrlich, S.D. (2013) Fiber. University of Maryland Medical Centre (UMMC), Baltimore.

[14] Threapleton, D.E., Greenwood, D.C., Evans, C.E., Cleghorn, C.L., Nykjaer, C., Woodhead, C., Cade, J.E., Gale, C.P. and Burley, V.J. (2013) Dietary Fiber Intake and Risk of First Stroke: A Systematic Review and Meta-Analysis. Stroke, 44, 1360-1368. http://dx.doi.org/10.1161/STROKEAHA.111.000151

[15] McCready, R.M., Guggolz, J., Silviera, V. and Owens, H.S. (1950) Determination of Starch and Amylose in Vegetables. Analytical Chemistry, 22, 1156-1158. http://dx.doi.org/10.1021/ac60045a016

[16] University of Canterbury (2015) Determination of Vitamin C Concentration by Titration. University of Canterbury, Christchurch.

[17] Achikanu, C.E., Eze-Steven, P.E., Ude, C.M. and Ugwuokolie, O.C. (2013) Determination of the Vitamin and Mineral Composition of Common Leafy Vegetables in South Eastern Nigeria. International Journal of Current Microbiology and Applied Sciences, 2, 347-353.

[18] Chenarda, C.H., Kopsellb, D.A. and Kopsell, D.E. (2005) Nitrogen Concentration Affects Nutrient and Carotenoid Accumulation in Parsley. Journal of Plant Nutrition, 28, 285-297.

[19] http://articles.mercola.com/sites/articles/archive/2013/08/03/cabbage.aspx 